\title{
Human Monocyte Colony-stimulating Factor Stimulates the Gene Expression of Monocyte Chemotactic Protein-1 and Increases the Adhesion of Monocytes to Endothelial Monolayers
}

\author{
Yeun-Jund Shyy, Lori L. Wickham, Joseph P. Hagan, Hsyue-Jen Hsieh, Ying-Li Hu, \\ Simon H. Telian, Anthony J. Valente, ${ }^{*}$ K-L. Paul Sung, and Shu Chien \\ Institute for Biomedical Engineering and Department of Applied Mechanics and Engineering Sciences-Bioengineering, \\ University of California, San Diego, La Jolla, California 92093-0412; and *Department of Pathology, \\ The University of Texas Health Science Center, San Antonio, Texas 78284
}

\section{Abstract}

The stimulation of the human umbilical vein endothelial cell (HUVEC) with recombinant human monocyte-derived colonystimulating factor (MCSF) increased the gene expression of monocyte chemotactic protein (MCP-1). Northern blot analysis indicated that $50 \mathrm{U} / \mathrm{ml}$ of MCSF is the optimal concentration for this effect. The elevation of MCP-1 mRNA started as early as $1 \mathrm{~h}$ after stimulation and was maintained for at least 8 h. An increased MCP-1 level in MCSF-treated HUVEC was also demonstrated at the protein level by immunocytochemical staining using a polyclonal MCP-1-specific antibody. HUVEC activated by $50 \mathrm{U} / \mathrm{ml}$ of MCSF for $5 \mathrm{~h}$ showed a stronger immunofluorescence staining than control cells. Micropipette separation of THP-1 monocytes from HUVEC showed that the activation of both THP-1 and endothelium by MCSF led to an increase in the separation force by more than three times $\left(36.2 \pm 6.7 \times 10^{-4}\right.$ vs. 9.6 $\left.\pm 3.6 \times 10^{-4} \mathrm{dyn}\right)$. An increased adhesiveness was also observed after MCSF activation of peripheral blood monocytes and HUVEC $\left(16.7 \pm 2.7 \times 10^{-4}\right.$ vs. $5.2 \pm 0.9$ $\left.\times 10^{-4} \mathrm{dyn}\right)$. The increased adhesive force in both systems was blocked by the use of anti-MCP-1 (5.5 $\pm 0.8 \times 10^{-4}$ and 6.8 \pm 1.1 $\times 10^{-4} \mathrm{dyn}$ ). Similar results were obtained in experiments in which only HUVEC, but not monocytes, were activated by MCSF. This increased adhesion of untreated monocytes to MCSF-activated HUVEC was also blocked by the addition of anti-MCP-1. In contrast, experiments in which only THP-1 or peripheral blood monocytes, but not HUVEC, were treated with MCSF did not show a significant increase of adhesion between these cells. These results indicate that MCSF augments monocyte-endothelium interaction primarily by its action on the endothelial cell and that this function is probably mediated through an increased expression of MCP-1. The MCSF / MCP-1-dependent adhesive mechanism might be operative in the arterial wall in vivo to lead to the trapping of the infiltrated monocyte-macrophage in the subendothelial space

Preliminary results of this study were presented at the Annual Meeting of the Federation of American Societies for Experimental Biology (1992. FASEB [Fed. Am. Soc. Exp. Biol.] J. 6:1891a).

Address correspondence to Dr. Shu Chien, Institute for Biomedical Engineering, University of California, San Diego, La Jolla, CA 920930412.

Received for publication 16 June 1992 and in revised form 16 March 1993.

J. Clin. Invest.

(C) The American Society for Clinical Investigation, Inc. $0021-9738 / 93 / 10 / 1745 / 07 \$ 2.00$

Volume 92, October 1993, 1745-1751 during atherogenesis. (J. Clin. Invest. 1993. 92:1745-1751.) Key words: atherosclerosis • cellular interaction • chemotaxis • micropipette aspiration $\bullet$ monocyte infiltration

\section{Introduction}

The intimal recruitment of peripheral blood monocytes to the lesion-prone areas of the arterial tree is an important early event in atherogenesis. The recruited monocytes undergo a differentiation step to become macrophages and may uptake and degrade plasma-derived LDL to develop into foam cells (1-3). The monocyte chemotactic protein (MCP-1) ${ }^{1}$ and monocyte colony-stimulating factor (MCSF) are two important cytokines involved in atherogenesis. MCP-1 is a glycoprotein with a molecular mass of $14 \mathrm{kD}$ and is expressed in vascular endothelium (4-6), vascular smooth muscle cells $(7,8)$, monocytes (9-11), and fibroblasts (12). Its primary function is to serve as a chemoattractant for monocytes (13). The MCP-1 gene belongs to an early response small gene superfamily (14-16). MCSF, also known as CSF-1, is a hematopoietic growth factor stimulating the differentiation and proliferation of monocytic progenitor cells $(17,18)$. MCSF is also expressed in vascular cells $(19,20)$ and is a glycosylated homodimer with a molecular mass of $45 \mathrm{kD}$ (21).

Minimally modified LDL (MM-LDL) has been shown to activate the expression of both MCP-1 and MCSF in cultured endothelial cells and in mice models in vivo (22-24). Transmigration of monocytes into the subendothelial space induced by LDL was inhibited by antibody to MCP-1 (25). MCSF has been shown to enhance the clearance of LDL in experimental animals $(26,27)$, and the uptake and degradation of acetylated LDL in cultured macrophages (28). Both MCP-1 and MCSF have been located in atherosclerotic lesions of humans and rabbit models $(19,29,30)$. Although these two cytokines have been implicated in atherogenesis by many investigators, little direct evidence is available concerning the roles they play in the accumulation of monocyte-macrophages in the arterial wall.

In the present study, we provide evidence that recombinant human MCSF activates MCP-1 gene expression in the human umbilical vein endothelial cell (HUVEC). In addition, using a micropipette aspiration technique, we have found that MCSF acts on the endothelium to increase the adhesive force between monocytes and HUVEC, and that this MCSF-induced adhesion is blocked by an antibody specific to MCP-1. These find-

1. Abbreviations used in this paper: HUVEC, human umbilical vein endothelial cell; MCSF, monocyte-derived colony-stimulating factor; MCP-1, monocyte chemotactic protein; MM-LDL, minimally modified low density lipoprotein; 
ings suggest that MCSF may enhance monocyte adhesion as a result of an increase of MCP-1 gene expression in the endothelium. The roles of these two cytokines in monocyte-endothelial adhesion may have significant implications in the transendothelial migration of monocytes in atherogenesis.

\section{Methods}

Cell cultures. HUVEC were isolated from the human umbilical cord as described by Jaffe et al. (31). The cells were grown in M-199 media containing $15 \%$ FCS supplemented with $2 \mathrm{mM} \mathrm{L-glutamine,} 100 \mathrm{U} / \mathrm{ml}$ penicillin, $100 \mu \mathrm{g} / \mathrm{ml}$ streptomycin, and $1 \mathrm{mM}$ sodium pyruvate. All the cells used were before passage seven. Human peripheral blood monocytes were isolated from freshly drawn blood by first mixing 10 parts of the blood with 1 part of $0.9 \% \mathrm{NaCl}$ (wt/ vol) containing 6\% dextran 500. After the erythrocytes had settled, the leukocyte-rich plasma was layered on NycoPrep 1.068 (Accurate Chemical Co., Westbury, NY) followed by centrifugation at $600 \mathrm{~g}$ for $15 \mathrm{~min}$. The NycoPrep 1.068 layer was suspended with $0.9 \% \mathrm{NaCl}$ containing $0.13 \%$ (wt/ vol ) EDTA and $1 \%$ FCS. The cell suspension was further centrifuged at $600 \mathrm{~g}$ for $7 \mathrm{~min}$. Platelets were finally removed by suspending the cell pellet in Hank's buffer and layering the cell suspension on NycoPrep 1.063 for centrifugation at $350 \mathrm{~g}$ for $5 \mathrm{~min}$. The monocyte pellet was then suspended in RPMI 1640 supplemented with 10\% FCS, 2 mM L-glutamine, $100 \mathrm{U} / \mathrm{ml}$ penicillin, $100 \mu \mathrm{g} / \mathrm{ml}$ streptomycin, and 100 $\mu \mathrm{M} \beta$-mercaptoethanol. The isolated cells were used within $12 \mathrm{~h}$ after isolation. The human monocytic cell line THP-1 was obtained from the American Type Culture Collection (Rockville, MD) and maintained in RPMI as described above. All cell cultures were maintained in a humidified $5 \% \mathrm{CO}_{2}, 95 \%$ air incubator at $37^{\circ} \mathrm{C}$.

RNA isolation and Northern blot analysis. HUVEC grown to confluency were washed twice with PBS and stimulated with recombinant human MCSF (Genzyme, Boston, MA). Total cellular RNA was isolated by using the guanidinium isothiocyanate $/ \mathrm{CsCl}$ method as previously described (32). In brief, the monolayer was washed and lysed with $4 \mathrm{M}$ guanidium isothiocyanate. The cell extract was layered on a cushion of $5.7 \mathrm{M} \mathrm{CsCl}$ and ultracentrifuged at $42,000 \mathrm{rpm}$ for $20 \mathrm{~h}$. The RNA sediment on the bottom of the ultracentrifuge tube was recovered and purified by ethanol precipitation. $20 \mu \mathrm{g}$ of the isolated RNA from each sample was loaded on a $1.5 \%$ formaldehyde agarose gel and subjected to electrophoresis. RNA was transferred to a nylon membrane for hybridization at $42^{\circ} \mathrm{C}$ for $18 \mathrm{~h}$ with either a ${ }^{32} \mathrm{P}$-labeled oligonucleotide 48 mer complimentary to the coding sequence of human MCP-1 or ${ }^{32} \mathrm{P}$-labeled 0.6-kb baboon vascular smooth muscle cell MCP-1 cDNA. The hybridization buffer contained $50 \%(\mathrm{vol} / \mathrm{vol})$ formamide, $5 \times$ SSC, $0.5 \times$ Denhardt's solution, $0.1 \%$ (vol/vol) SDS, and $100 \mu \mathrm{g} / \mathrm{ml}$ salmon sperm DNA. The membrane was then washed and exposed to Kodak X-Omat XAR film at $-70^{\circ} \mathrm{C}$.

Immunocytochemistry and fluorescence microscopy. The HUVEC cultures on coverslips contained in six-well culture plates were grown to confluency and stimulated with $\operatorname{MCSF}(50 \mathrm{U} / \mathrm{ml})$. After incubation at $37^{\circ} \mathrm{C}$ for $5 \mathrm{~h}$, the HUVEC monolayers were washed with warm PBS and fixed with $1 \%$ (vol/vol) formalin in PBS for $10 \mathrm{~min}$. The first antibody, anti-MCP-1, is a polyclonal antibody raised in the rabbit against a baboon MCP-1 $(8,33)$. Anti-MCP-1, $2 \%$ (vol/vol) in PBS containing $2 \%$ albumin, was applied to the fixed HUVEC and incubated at $37^{\circ} \mathrm{C}$ for $1 \mathrm{~h}$, followed by three 5-min washes with PBS. The second antibody, tetramethylrhodamine isothiocyanate (TRITC)-conjugated goat anti-rabbit IgG (Sigma Chemical Co., St. Louis, MO) with a dilution of $1: 100$, was then introduced for a second incubation at $37^{\circ} \mathrm{C}$ for $1 \mathrm{~h}$. After three PBS washes, the coverslips were inverted and mounted on microscopic slides. An epi-fluorescence microscope (Microphot-FX; Nikon ) equipped with a diascopic phase-contrast attachment was used to study the fluorescence intensity in the HUVEC monolayer. The observation was made with an excitation filter at 450-490 $\mathrm{nm}$, a dichroic mirror at $510 \mathrm{~nm}$, and a barrier filter at $520 \mathrm{~nm}$.
Micropipette assay of the adhering force of monocytes to the $H U$ $V E C$ monolayer. The assay was performed on both the THP-1 monocytic cell line and freshly isolated peripheral blood monocytes. In coactivation experiments in which both monocytes and HUVEC were exposed to MCSF, the confluent HUVEC monolayer cultured in plastic chambers $(r=0.5 \mathrm{~cm})$ was first washed twice with warm culture medium, then incubated for $30 \mathrm{~min}$ with or without anti-MCP-1 (1\% [vol/vol]), and followed by the addition of $\operatorname{MCSF}(50 \mathrm{U} / \mathrm{ml})$. Monocytes ( $\sim 10^{4}$ cells) were washed twice with warm M-199 medium and added into the HUVEC chamber for $3 \mathrm{~h}$ of coincubation before the micropipette aspiration assay. In experiments in which only the HUVEC were activated, the monolayer was first treated with MCSF, or MCSF plus anti-MCP-1, for $3 \mathrm{~h}$. The activated monolayer was washed twice with warm M-199 medium and incubated with untreated monocytes for $1 \mathrm{~h}$ before the micropipette aspiration assay. In experiments in which only the monocytes were activated, THP-1 cells or peripheral blood monocytes were first incubated in M-199 media supplemented with MCSF, or MCSF plus anti-MCP-1, for $3 \mathrm{~h}$. The cells were washed twice and then added to the unstimulated HUVEC monolayer for $1 \mathrm{~h}$ of incubation before the aspiration assay.

The procedure of the micropipette aspiration has been described previously $(34,35)$. In brief, micropipettes with an internal radius $\left(R_{p}\right)$ of 1.6-3.3 $\mu \mathrm{m}$ were manipulated by using a hydraulic micromanipulator (Narishige Scientific Instrument Lab., Tokyo, Japan) mounted on the stage of an inverted microscope. The tip of the pipette was positioned in the cell chamber, and the wide end was connected to a pressure regulation system. Monocytes adhering to the HUVEC monolayer were randomly chosen and held at the tip of the pipette by the application of an initial aspiration pressure. When the force due to the aspiration pressure was insufficient to balance the adhesive force, the THP-1 would slip out of the micropipette when the latter was pulled away by micromanipulation. The aspiration pressure was increased stepwise until a critical separation pressure $\left(P_{c}\right)$ was attained, which led to the complete detachment of the THP-1 cell from the HUVEC monolayer as the micropipette was pulled away by micromanipulation. The critical separation force $\left(F_{c}\right)$ was calculated as:

$F_{c}=\pi R_{p}^{2} P_{c}$.

The experiments were performed at room temperature $\left(23-26^{\circ} \mathrm{C}\right)$ and the aspiration tests for multiple cells studied in the same chamber were usually accomplished within $1 \mathrm{~h}$. Analysis of the results indicated an invariance of the separating force vs. time elapsed within the period of testing.

Statistics. Results for the measurements made in each group of experiments were expressed as mean \pm SEM. Significance of difference was determined by using unpaired Wilcoxon test.

\section{Results}

MCSF stimulates the expression of MCP-1 in HUVEC. The increased level of MCP-1 gene transcripts in MCSF-treated HUVEC was demonstrated by Northern blot analysis. This elevation of expression was concentration dependent (Fig. 1). HUVEC treated with MCSF at concentrations ranging from 5 to $150 \mathrm{U} / \mathrm{ml}$ for $4 \mathrm{~h}$ showed a threshold concentration for MCP- $1 \mathrm{mRNA}$ expression at $25 \mathrm{U} / \mathrm{ml}$ and an optimal concentration at $50 \mathrm{U} / \mathrm{ml}$. Fig. 2 demonstrates that the stimulation was also time dependent. When the MCSF concentration was set at $50 \mathrm{U} / \mathrm{ml}$, the level of MCP-1 transcript increased at $1 \mathrm{~h}$, reached a peak at $4 \mathrm{~h}$, and was maintained at this elevated level for at least $8 \mathrm{~h}$.

MCSF-activation of HUVEC also caused an increase in MCP-1 at the protein level, as illustrated by imunofluorescence staining. Representative fluorescence microscopic fields of 
A
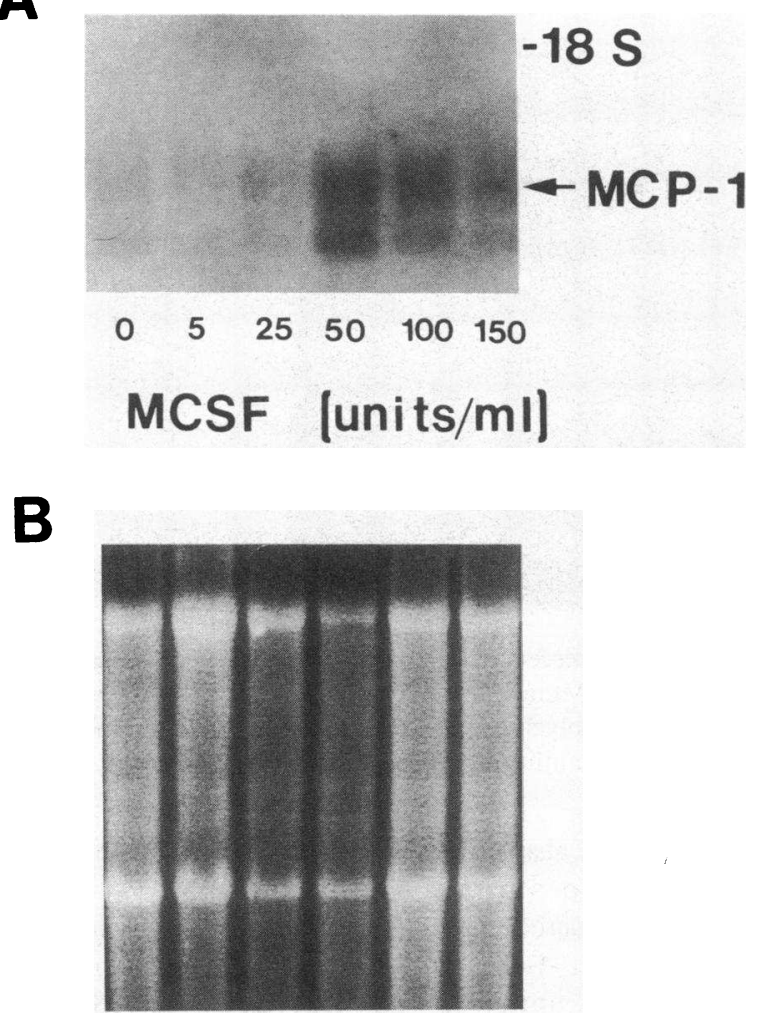

Figure 1. Northern blot analysis demonstrates that the stimulation of MCP-1 gene expression in HUVEC is MCSF concentration dependent. $(A)$ Confluent HUVEC cells were stimulated for $4 \mathrm{~h}$ with various concentrations of recombinant human MCSF as indicated. Total cellular RNA were isolated and Northern blots were performed as described. Blots were probed for MCP-1-specific transcripts. $(B)$ Ethidium bromide staining demonstrates that equal amounts of total RNA were loaded on each lane.

MCSF-treated and nonactivated HUVEC monolayers are shown in Fig. 3. The fluorescence intensity in endothelial cells activated by $50 \mathrm{U} / \mathrm{ml}$ of MCSF for $5 \mathrm{~h}$ is stronger than that in control cells, indicating that the level of antigenic MCP-1 in MCSF-treated HUVEC was increased by the treatment.

MCSF increases the adhesive force between THP-1 and HUVEC, and this effect is blocked by anti-MCP-1. We tested whether the treatment of HUVEC and monocytes by MCSF (coactivation experiments) increased their adhesion by measuring the critical separation force in micropipette aspiration tests. Separation forces were calculated and subjected to statistical analysis. In a few cases, monocytes could not be separated from the HUVEC even with a aspiration pressure as high as $1,000 \mathrm{mmH}_{2} \mathrm{O}$; this magnitude of aspiration pressure was used to calculate the separation force for these nonseparable cells. As shown in Fig. 4, while a $F_{c}$ of $36.2 \pm 6.7 \times 10^{-4}$ dyn was needed to separate the THP-1 from HUVEC in these coactivation experiments, a value of $9.6 \pm 3.6 \times 10^{-4}$ dyn was found in control experiments. The addition of anti-MCP-1 blocked the increase in cellular adhesion caused by MCSF and reduced the separation force to $5.5 \pm 0.8 \times 10^{-4}$ dyn. As indicated in Table I, similar results were also obtained in experiments in which peripheral blood monocytes were aspirated from HUVEC mono- layers. The critical separation forces are $16.7 \pm 2.7 \times 10^{-4}$, $5.2 \pm 0.9 \times 10^{-4}$, and $6.8 \pm 1.1 \times 10^{-4}$ dyn for MCSF treated, control, and (MCSF + anti-MCP-1) treated experiments, respectively. The strength of adhesion may also be expressed as the percentage of monocytes that can be separated with a force $<10^{-3}$ dynes. While $85.0 \%$ of the THP-1 and $85.7 \%$ of the peripheral blood monocytes were separable with this force level in controls, only 38.0 and $48.6 \%$, respectively, were separable in the MCSF-treated group; $91.7 \%$ of the THP-1 and $77.1 \%$ of the peripheral blood monocytes were separated in the MCSF + anti-MCP-1 experiments.

MCSF augments cellular interaction primarily by its action on the endothelium. The MCSF-induced promotion of adhesion of monocytes on HUVEC monolayers may result from its action on either the monocytes, the endothelial cells, or both cell types. This was assessed by determining the cellular adhesive force in additional sets of experiments in which only the HUVEC or the monocytes were activated by MCSF. When only the HUVEC monolayer had been activated by MCSF, the $F_{c}$ values required to separate the untreated THP-1 and peripheral blood monocytes were $33.1 \pm 6.7$ and $22.5 \pm 4.0 \times 10^{-4}$ dyn, respectively. Such increased adhesiveness by MCSF was blocked by the addition of anti-MCP-1. The $F_{c}$ values were reduced to $9.7 \pm 2.2 \times 10^{-4}$ dyn for THP-1 and $6.3 \pm 1.5 \times 10^{-4}$ dyn for peripheral blood monocytes when the HUVEC had been incubated with MCSF + anti-MCP-1. These $F_{c}$ values for MCSF- and anti-MCP-1-treated cells were statistically not sig-
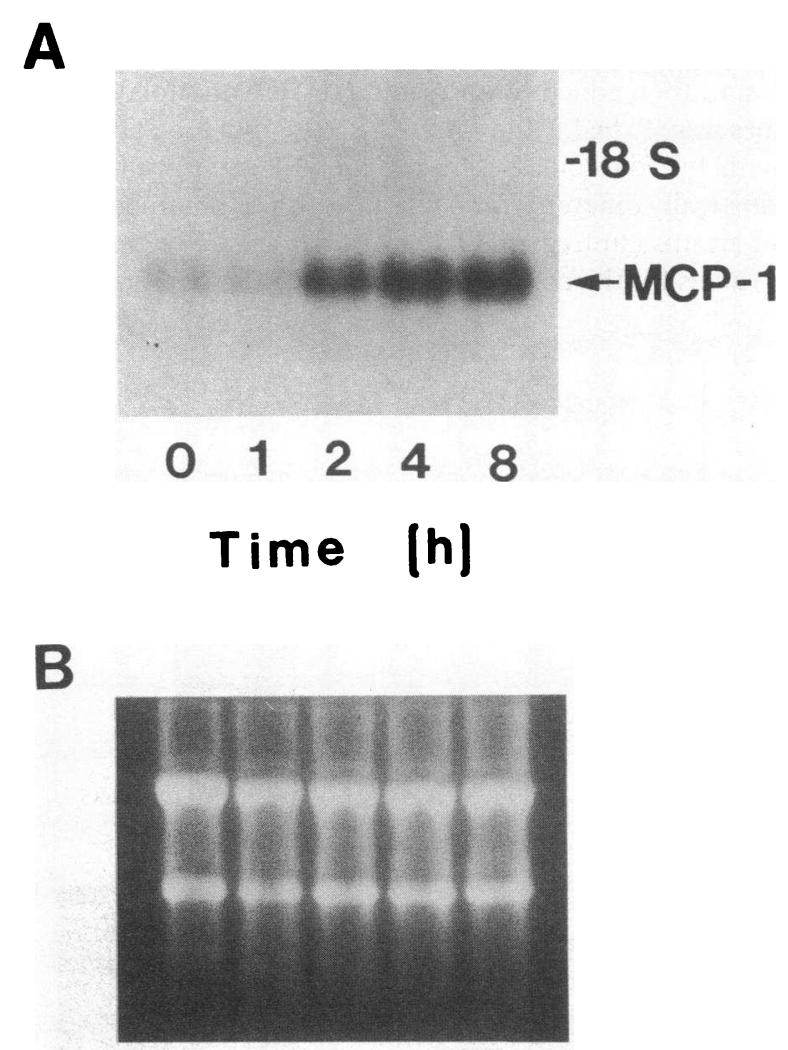

Figure 2. Northern blot analysis shows the time course of MCP-1 gene expression after the addition of $50 \mathrm{U} / \mathrm{ml}$ of MCSF to $\operatorname{HUVEC}(A)$, and ethidium bromide staining demonstrates that equal amounts of RNA were loaded $(B)$. 


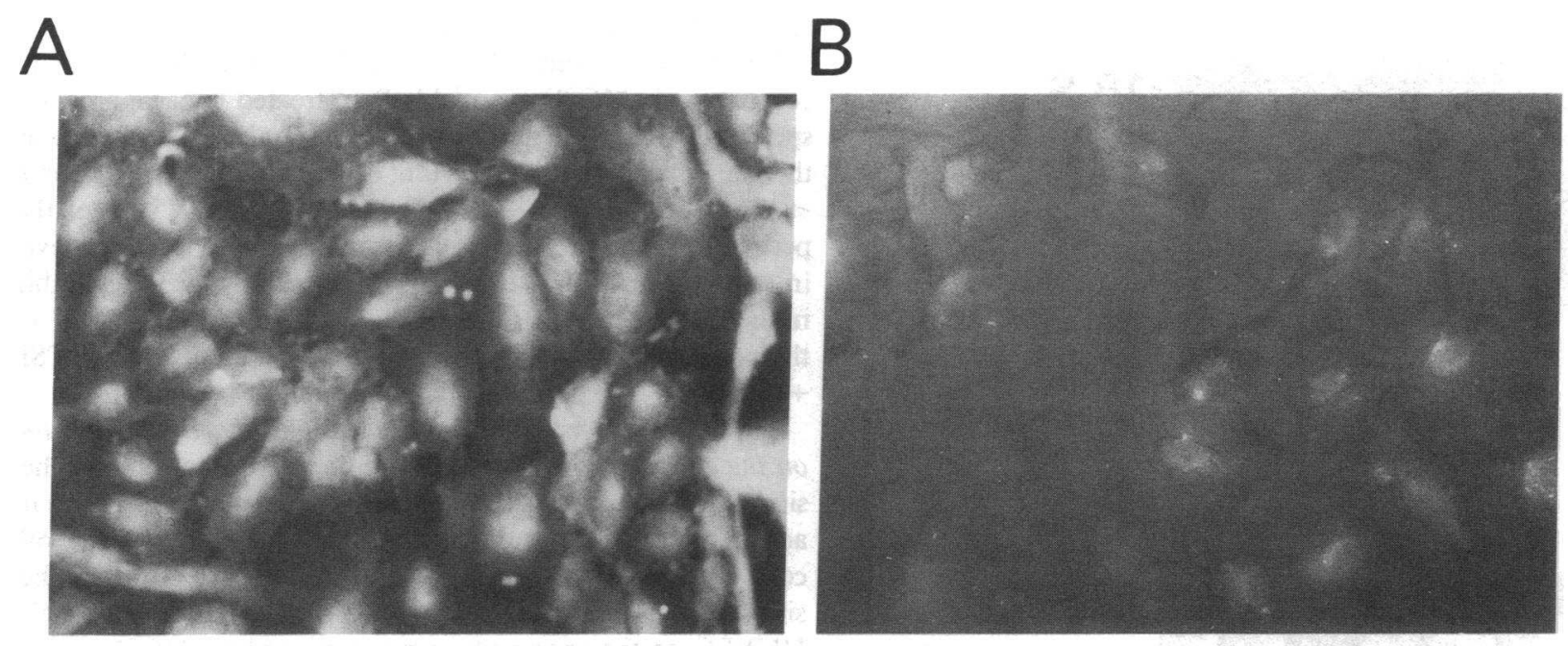

Figure 3. The detection of MCP-1 in MCSF-treated HUVEC as demonstrated by immunofluorescence staining. Confluent HUVEC monolayers were incubated in medium containing $50 \mathrm{U} / \mathrm{ml} \mathrm{MCSF}(A)$, or in medium only $(B)$, for $5 \mathrm{~h}$. Monolayers were washed with PBS followed by fixation in $1 \%$ formalin for 10 min. Antigenic MCP-1 in fixed HUVEC was first recognized by polyclonal anti-MCP-1, which was in turn detected with a tetramethylrhodamine isothiocyanate (TRITC)-conjugated goat anti-rabbit IgG second antibody.

nificantly different from those in control experiments on untreated cells. The percentages of THP-1 cells separable by forces $<10^{-3}$ dyn for the control, MCSF-treated, and MCSF + anti-MCP-1-treated HUVEC were $89.8,30.0$, and $76.2 \%$, respectively. Similarly, the percentages of peripheral blood monocytes separable from these three types of treated HUVEC were $82.9,51.4$, and $88.6 \%$, respectively.

In experiments in which monocytes were first activated by MCSF and then added to untreated HUVEC monolayers, the $F_{c}$ values were $9.2 \pm 4.2$ and $4.1 \pm 0.7 \times 10^{-4}$ dyn for THP-1 and peripheral blood monocytes, respectively. These $F_{c}$ values were not statistically different from either the values obtained for the control groups (untreated THP- 1 and HUVEC) in this series or the values for the control groups in the coactivation experi- ments. They were also not significantly different from the $F_{c}$ values required to separate MCSF + anti-MCP-1-treated monocytes. The percentages of control, MCSF-treated, and MCSF + anti-MCP-1-treated THP-1 cells separable by forces $<10^{-3}$ dyn from untreated HUVEC were 89.8, 88.9, and $100 \%$, respectively. The percentages of these three groups of peripheral blood monocytes separable by the same magnitude of force from untreated HUVEC were $82.9,91.4$, and $85.7 \%$, respectively.

\section{Discussion}

There are three central findings in this study. First, MCSF stimulates the expression of MCP-1 in endothelial cells. Second, the

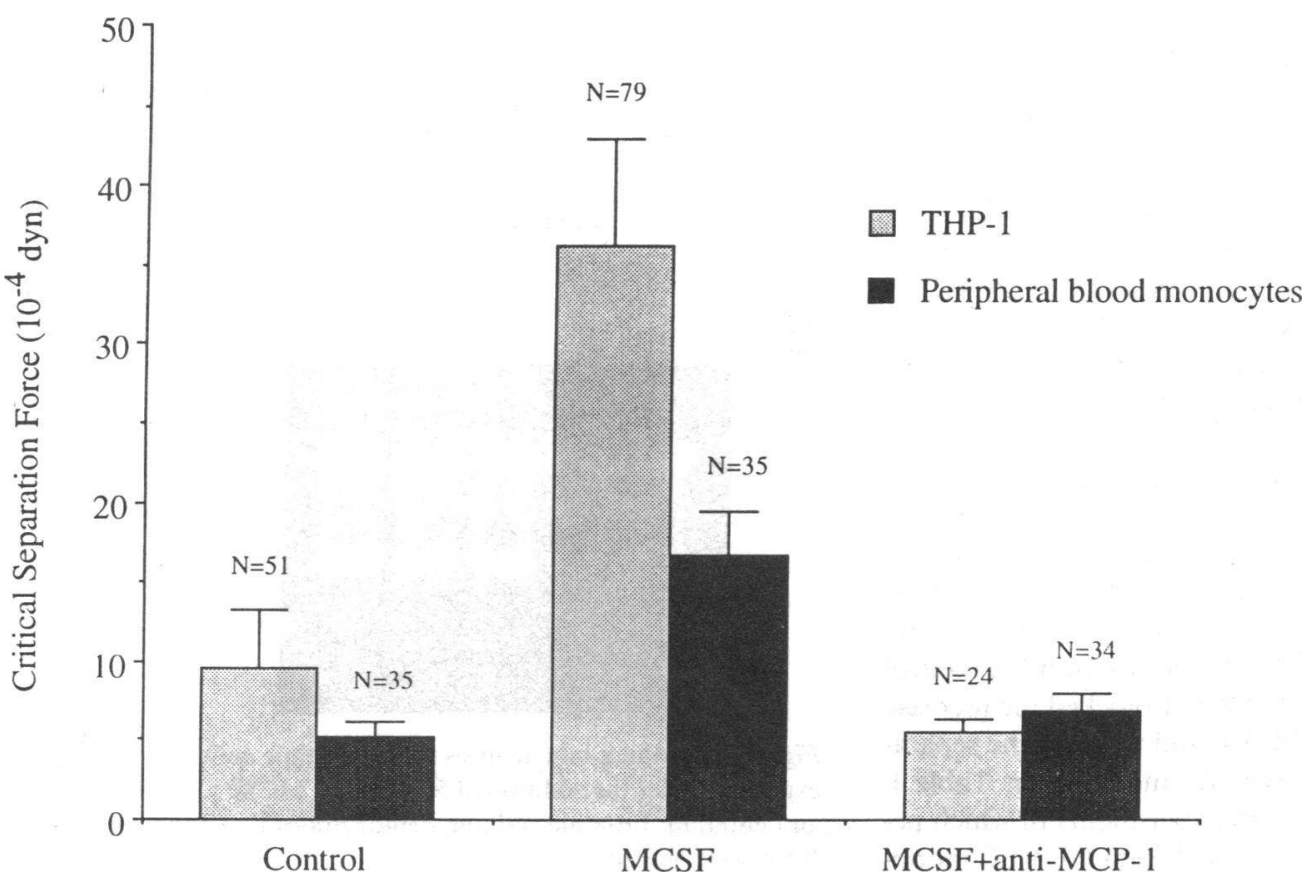

Figure 4. The critical separation force $\left(F_{c}\right)$ required to separate THP-1 and peripheral blood monocytes from HUVEC was increased after coactivation with MCSF, and the effect was blocked by anti-MCP-1. The confluent HUVEC monolayer was incubated for $30 \mathrm{~min}$ with or without anti-MCP-1 (1\% [ $\mathrm{vol} / \mathrm{vol}]$ ), and was followed by the addition of MCSF ( $50 \mathrm{U} /$ $\mathrm{ml})$. THP-1 monocytes or freshly isolated peripheral blood monocytes were then added into the HUVEC chamber for $3 \mathrm{~h}$ of coincubation before the micropipette aspiration assay. Bars represent SEM. $(N)$ Number of monocytes aspirated. 
Table I. The $F_{c}$ between THP-1, or Peripheral Blood Monocytes, and HUVEC Monolayers

\begin{tabular}{|c|c|c|c|c|c|}
\hline \multirow[b]{2}{*}{ Experiment } & \multirow[b]{2}{*}{ Treatment } & \multicolumn{2}{|c|}{$F_{c}\left(10^{-4} \mathrm{dyn}\right)^{*}$} & \multicolumn{2}{|c|}{ Percent separation at $10^{-3}$ dyn } \\
\hline & & THP-1 & $\begin{array}{c}\text { Peripheral } \\
\text { blood monocytes }\end{array}$ & THP-1 & $\begin{array}{c}\text { Peripheral } \\
\text { blood monocytes }\end{array}$ \\
\hline \multirow[t]{3}{*}{ Coactivation } & Control & $9.6 \pm 3.6(n=51)^{\ddagger}$ & $5.2 \pm 0.9(n=35)$ & 85.0 & 85.7 \\
\hline & MCSF & $36.2 \pm 6.7^{8}(n=79)$ & $16.7 \pm 2.7^{8}(n=35)$ & 38.0 & 48.6 \\
\hline & MCSF + anti-MCP-1 & $5.5 \pm 0.8(n=24)$ & $6.8 \pm 1.1(n=34)$ & 91.7 & 77.1 \\
\hline \multirow{4}{*}{$\begin{array}{l}\text { HUVEC activation } \\
\text { (monocyte untreated) }\end{array}$} & & & & & \\
\hline & Control" & $5.3 \pm 0.9(n=59)$ & $5.4 \pm 0.9(n=35)$ & 89.8 & 82.9 \\
\hline & MCSF & $33.1 \pm 6.7^{\S}(n=42)$ & $22.5 \pm 4.0^{\S}(n=35)$ & 30.0 & 51.4 \\
\hline & $\mathrm{MCSF}+$ anti-MCP-1 & $9.7 \pm 2.2(n=21)$ & $6.3 \pm 1.5(n=35)$ & 76.2 & 88.6 \\
\hline \multirow{4}{*}{$\begin{array}{l}\text { Monocyte activation } \\
\text { (HUVEC untreated) }\end{array}$} & & & & & \\
\hline & Control" & $5.3 \pm 0.9(n=59)$ & $5.4 \pm 0.9(n=35)$ & 89.8 & 82.9 \\
\hline & MCSF & $9.2 \pm 4.2^{1}(n=27)$ & $4.1 \pm 0.7^{1}(n=35)$ & 88.9 & 91.4 \\
\hline & MCSF + anti-MCP-1 & $3.2 \pm 0.4(n=27)$ & $5.3 \pm 0.8(n=35)$ & 100.0 & 85.7 \\
\hline
\end{tabular}

${ }^{*}$ Mean \pm SEM. ${ }^{\ddagger}$ Total number of cells tested. ${ }^{\$} P<0.0002$ between MCSF and control, and also between MCSF and (MCSF + anti-MCP-1). "The control experiments in HUVEC activation and monocytes activation were the same. ' $F_{c}$ values were not statistically different from those for control and (MCSF + anti-MCP-1) groups.

adhesion of monocytes, i.e., THP-1 or peripheral blood monocytes, to HUVEC monolayers is enhanced by MCSF, and this effect is blocked by an antibody specific to MCP-1. Third, such augmentation of cellular interaction by MCSF is primarily through its action on the endothelial cell rather than the monocyte.

Cushing et al. and Rajavashisth et al. $(22,23)$ observed increased levels of MCSF and MCP-1 transcripts in vascular endothelium treated with MM-LDL. Our finding of the upregulation of MCP-1 transcripts in HUVEC by an optimal concentration of MCSF (Fig. 1) suggests that the signal transduction pathway leading to the MCP-1 gene expression in response to MM-LDL may be partially mediated via MCSF. In addition to MM-LDL, the stimulation of gene expressions of MCSF and MCP-1 in cultured vascular endothelium by common stimuli has been reported in many other conditions, including plateletderived growth factor (PDGF) $(9,36,37)$, bacterial LPS $(6$, $19)$, recombinant human tumor necrosis factor- $\alpha$ (TNF- $\alpha)(4$, $6,19)$, and recombinant human IL-1 $(4,6,19,38)$. In accordance with the present findings, the induced MCSF in the endothelial cells activated by these stimuli would further increase the gene expression of MCP-1. An optimal stimuli concentration to induce the expression of MCP-1 is not unique to MCSF. For example, $10^{-7} \mathrm{M}$ of 12-O-tetradecanoyl-phorbol-13-acetate (TPA) and $100 \mathrm{ng} / \mathrm{ml}$ of LPS have been shown to be the optimal concentrations required to induce the maximum levels of MCP-1 transcripts in HUVEC or fibroblasts $(32,39)$. In a separate time course experiment, we found that the level of MCP-1 transcripts in cells treated with MCSF for $16 \mathrm{~h}$ was similar to those treated for $4 \mathrm{~h}$. This together with the data shown in Fig. 2 indicate that the induced increase in the levels of MCP-1 message sustained for at least $8 \mathrm{~h}$. Thus, the signal transduction pathway in MCSF-induced MCP-1 gene activation may differ at least partly from that in the transient expression of MCP-1 in TPA-stimulated HUVEC (32) or in LPSstimulated BALB/c 3T3 cells (39).

Micropipette aspiration has been used widely in investigations on cellular interactions $(34,35)$. In the present study, this technique was used to assess the adhesive force between monocytes and MCSF-activated HUVEC. We also performed the conventional attachment assays (40), and the preliminary results are consistent with the findings in the present micropipette tests. The micropipette aspiration technique has the important advantage of assessing the adhesive force of each attached monocyte individually and quantitatively, information that can not be obtained in the attachment assay. The coactivation of either THP-1 or freshly isolated peripheral blood monocytes and HUVEC with MCSF caused more than threefold increases in the critical separation force when compared with that in controls, and this increased adhesion was effectively blocked by anti-MCP-1 (Fig. 4). These data suggest that MCP1 may act not only as a chemoattractant molecule $(10,13)$, but also as a factor for increasing the strength of monocyte-endothelium interaction. It is possible that the induction pathway for MCSF/MCP-1 expression interacts with the regulatory pathway for the expression of adhesion molecules such as the endothelium-leukocyte adhesion molecule (ELAM-1), intercellular adhesion molecule (ICAM-1), and vascular cell adhesion molecule ( VCAM-1) on the surface of the endothelial cell. Although there are no previous reports that MCSF leads to the expression of adhesion molecules on endothelium, the above hypothesis is supported indirectly by the observations in vivo that VCAM-1 and ICAM- 1 are expressed in the atherosclerotic lesions in which MCSF/MCP-1 expression are known to be active $(41,42)$. In addition, the stimuli that cause an increase in the gene expression of both MCSF and MCP-1 have all been shown to increase the adhesion of monocytes to endothelial cells (43), and this may be due to the upregulation of adhesion molecules (44-47).

Our results also suggest that MCSF promotes monocyteendothelium adhesion by its action primarily on the endothelial cells rather than the monocytes. That the activation of leukocytes is less critical in promoting their adhesion to endothelium is also supported by previous reports that the activation of monocytes with endothelin or PDGF did not increase their chemotaxis (48), and that TPA or TNF stimulation of high 
endothelial venule cells, but not lymphocytes, increased the cellular interaction (49). During the preparation of this manuscript, MCSF-induced MCP-1 gene expression in monocytes was reported (10). The question as to why such MCP-1 expression in the monocyte did not bring about an enhanced adhesion to endothelium needs further investigation.

That MCSF increases both the gene expression of MCP-1 and the adhesion of monocytes to endothelium may be signifcant not only in the initial cellular interaction, but also the subsequent development of atherosclerosis in the arterial wall. Endothelium activated by the exposure to atherosclerotic risk factors such as modified LDL may release MCP-1 in vivo. As a consequence, there may be an increase in the monocyte recruitment and in the adhesion strength between monocytes and endothelium, which may lead to an increase of monocyte penetration into the arterial wall. This hypothesis is supported by the in vitro data that antibody specific to MCP-1 blocks the transmigration of monocytes into the subendothelial space induced by MM-LDL (25). In addition, intimal monocyte-macrophages probably synthesize and release MCSF, which may further stimulate the expression of MCP-1 in the surrounding vascular tissue. Thus, monocyte-macrophages would be further recruited from circulation to the intima with subsequent LDL uptaking and ultimately develop into foam cells. This would be an important mechanism in plaque progression. The possibility of a reciprocal regulation, i.e., whether MCP-1 can increase the gene expression of MCSF in the endothelium, has not yet been investigated. If such a relationship exists, then a MCSF/MCP-1 autocrine system might be operative in the arterial wall in vivo.

\section{Acknowledgments}

We thank Drs. Daniel Steinberg and Thomas Carew for helpful discussions, and Dr. Amy L-P. Sung for the use of her facility in Northern blot analysis. We also thank Gerald Norwich and Fausto Maldonado for technical assistance.

This study was supported in part by U.S. Public Health Service research grants HL-19454, HL-43026, HL-44147, and HL-26890, and training grant HL-07089 from the National Heart, Lung, and Blood Institute.

\section{References}

1. Steinberg, D. 1983. Lipoproteins and atherosclerosis. Arteriosclerosis. 3:283-301.

2. Hansson, G. K., L. Jonasson, P. S. Seifert, and S. Stemme. 1989. Immune mechanisms in atherosclerosis. Arteriosclerosis. 9:567-578.

3. Schwartz, C. J., A. J. Valente, E. A. Sprague, J. L. Kelley, and R. M. Nerem. 1991. The pathogenesis of atherosclerosis: an overview Clin. Cardiol. 14(2 Suppl 1):11-16.

4. Rollins, B. J., T. Yoshimura, E. J. Leonard, and J. S. Pober. 1990. Cytokine-activated human endothelial cells synthesize and secrete a monocyte chemoattractant, MCP-1/JE. Am. J. Pathol. 136:1229-1233.

5. Rollins, B. J., and J. S. Pober. 1991. Interleukin-4 induces the synthesis and secretion of MCP-1/JE by human endothelial cells. Am. J. Pathol. 138:13151319.

6. Bussolino, F., M. De Rossi, A. Sica, F. Colotta, J. M. Wang, E. Bocchietto, I. M. Padura, A. Bosia, E. Dejana, and A. Mantovani. 1991. Murine endothelioma cell lines transformed by polyoma middle $\mathrm{T}$ oncogene as target for and producers of cytokines. J. Immunol. 147:2122-2129.

7. Jiang, Y., A. J. Valente, M. J. Williamson, L. Zhang, and D. T. Graves. 1990. Post-translational modification of a monocyte-specific chemoattractant synthesized by glioma, osteosarcoma, and vascular smooth muscle cells. J. Biol. Chem. 265:18318-18321.

8. Valente, A. J., D. T. Graves, C. E. Vialle-Valentin, R. Delgado, and C. J. Schwartz. 1988. Purification of a monocyte chemotactic factor secreted by nonhuman primate vascular cells in culture. Biochemistry. 27:4162-4168.
9. Rollins, B. J., P. Stier, T. Ernst, and G. G. Wong. 1989. The human homo$\log$ of the JE gene encodes a monocyte secretory protein. Mol. Cell. Biol. 9:46874695 .

10. Colotta, F., A. Borre, J. M. Wang, M. Tattanelli, F. Maddalena, N. Polentarutti, G. Peri, and A. Mantovani. 1992. Expression of a monocyte chemotactic cytokine by human mononuclear phagocytes. J. Immunol. 148:760-765.

11. Yoshimura, T., N. Yuhki, S. K. Moore, E. Appella, M. I. Lerman, and E. J. Leonard. 1989. Human monocyte chemoattractant protein-1 (MCP-1) fulllength cDNA cloning, expression in mitogen-stimulated blood mononuclear leukocytes, and sequence similarity to mouse competence gene JE. FEBS (Fed. Eur. Biochem. Soc.) Lett. 244:487-493.

12. Hall, D. J., C. Brownlee, and C. D. Stiles. 1989. Interleukin-1 is a potent regulator of JE and $\mathrm{KC}$ gene expression in quiescent BALB/c fibroblasts. J. Cell. Physiol. 141:154-159.

13. Rollins, B. J., A. Walz, and M. Baggiolini. 1991. Recombinant human MCP-1 / JE induces chemotaxis, calcium flux, and the respiratory burst in human monocytes. Blood. 78:1112-1116.

14. Kawahara, R. S., and T. F. Deuel. 1989. Platelet-derived growth factor-inducible gene JE is a member of a family of small inducible genes related to platelet factor 4. J. Biol. Chem. 264:679-682.

15. Wolpe, S. D., and A. Cerami. 1989. Macrophage inflammatory proteins 1 and 2: members of a novel superfamily of cytokines. FASEB (Fed. Am. Soc. Exp. Biol.) J. 3:2565-2573.

16. Sherry, B., and A. Cerami. 1991. Small cytokine superfamily. Curr. Opin. Immunol. 3:56-60.

17. Tushinski, R. J., and E. R. Stanley. 1985. The regulation of mononuclear phagocyte entry into $\mathrm{S}$ phase by the colony stimulating factor CSF-1. J. Cell. Physiol. 122:221-228.

18. Becker, S., M. K. Warren, and S. Haskill. 1987. Colony-stimulating factor-induced monocyte survival and differentiation into macrophage in serumfree cultures. J. Immunol. 139:3703-3709.

19. Clinton, S. K., R. Underwood, L. Hayes, M. L. Sherman, D. W. Kufe, and P. Libby. 1992. Macrophage colony-stimulating factor gene expression in vascular cells and in experimental and human atherosclerosis. Am. J. Pathol. 140:301316.

20. Seelentag, W. K., J. J. Mermod, R. Montesano, and P. Vassalli. Additive effects of interleukin 1 and tumor necrosis factor-alpha on the accumulation of the three granulocyte and macrophage colony-stimulating factor mRNAs in human endothelial cells. EMBO (Eur. Mol. Biol. Organ.) J. 6:2261-2265.

21. Das, S. K., and E. R. Stanley. 1982. Structure-function studies of a colony stimulating factor (CSF-1). J. Biol. Chem. 257:13679-13684.

22. Cushing, S. D., J. A. Berliner, A. J. Valente, M. C. Territo, M. Navab, F. Parhami, R. Gerrity, C. J. Schwartz, and A. M. Fogelman. 1990. Minimally modified low density lipoprotein induces monocyte chemotactic protein 1 in human endothelial cells and smooth muscle cells. Proc. Natl. Acad. Sci. USA 87:5134-5138.

23. Rajavashisth, T. B., A. Andalibi, M. C. Territo, J. A. Berliner, M. Navab, A. M. Fogelman, and A. J. Lusis. 1990. Induction of endothelial cell expression of granulocyte and macrophage colony-stimulating factors by modified low-density lipoproteins. Nature (Lond.). 344:254-257.

24. Liao, F., J. A. Berliner, M. Mehrabian, M. Navab, L. L. Demer, A. J. Lusis, and A. M. Fogelman. 1991. Minimally modified low density lipoprotein is biologically active in vivo in mice. J. Clin. Invest. 87:2253-2257.

25. Navab, M., S. S. Imes, S. Y. Hama, G. P. Hough, L. A. Ross, R. W. Bork A. J. Valente, J. A. Berliner, D. C. Drinkwater, H. Laks, and A. M. Fogelman. 1991. Monocyte transmigration induced by modification of low density lipoprotein in cocultures of human aortic wall cells is due to induction of monocyte chemotactic protein 1 synthesis and is abolished by high density lipoprotein. $J$. Clin. Invest. 88:2039-2046.

26. Shimano, H., N. Yamada, S. Ishibashi, K. Harada, A. Matsumoto, N. Mori, T. Inaba, K. Motoyoshi, H. Itakura, and F. Takaku. 1990. Human monocyte colony-stimulating factor enhances the clearance of lipoproteins containing apolipoprotein B-100 via both low density lipoprotein receptor-dependent and -independent pathways in rabbits. J. Biol. Chem. 265:12869-12875.

27. Shimano, H., N. Yamada, K. Motoyoshi, A. Matsumoto, S. Ishibashi, N. Mori, and F. Takaku. 1990. Plasma cholesterol-lowering activity of monocyte colony-stimulating factor (M-CSF). Ann. NY Acad. Sci. 587:362-370.

28. Ishibashi, S., T. Inaba, H. Shimano, K. Harada, I. Inoue, H. Mokuno, N. Mori, T. Gotoda, F. Takaku, and N. Yamada. 1990. Monocyte colony-stimulating factor enhances uptake and degradation of acetylated low density lipoproteins and cholesterol esterification in human monocyte-derived macrophages. J. Biol. Chem. 265:14109-14117.

29. Rosenfeld, M. E., S. Yla-Herttuala, B. A. Lipton, V. A. Ord, J. L. Witztum, and D. Steinberg. 1992. Macrophage colony-stimulating factor mRNA and protein in atherosclerotic lesions of rabbits and humans. Am. J. Pathol. 140:291300.

30. Ylä-Herttuala, S., B. A. Lipton, M. E. Rosenfeld, T. Särkioja, T. Yoshimura, E. J. Leonard, J. L. Witztum, and D. Steinberg. 1991. Expression of mono- 
cyte chemoattractant protein 1 in macrophage-rich areas of human and rabbit atherosclerotic lesions. Proc. Natl. Acad. Sci. USA. 88:5252-5256.

31. Jaffe, E. A., R. L. Nachman, C. G. Becker, and C. R. Minick. 1973. Culture of human endothelial cells derived from umbilical veins. J. Clin. Invest. 52:2745-2756.

32. Shyy, Y-J., Y-S. Li, and P. E. Kolattukudy. 1990. Structure of human monocyte chemotactic protein gene and its regulation by TPA. Biochem. Biophys. Res. Commun. 169:346-351.

33. Graves, D. T., Y. L. Jiang, M. J. Williamson, and A. J. Valente. 1989. Identification of monocyte chemotactic activity produced by malignant cells. Science (Wash. DC). 245:1490-1493.

34. Sung, K-L. P., L. A. Sung, M. Crimmins, S. J. Burakoff, and S. Chien. 1986. Determination of junction avidity of cytolytic T cell and target cell. Science (Wash. DC). 234:1405-1408.

35. Tözeren, A., K-L. P. Sung, L. A. Sung, M. L. Dustin, T. A. Springer, and S. Chien. 1992. Micromanipulation of adhesion of a Jurkat cell to a planar bilayer membrane containing lymphocyte function-associated antigen 3 molecules. $J$. Cell Biol. 116:997-1006.

36. Abboud, S. L., and M. Pinzani. 1991. Peptide growth factors stimulate macrophage colony-stimulating factor in murine stromal cells. Blood. 78:103109.

37. Rollins, B. J., E. D. Morrison, and C. D. Stiles. 1987. A cell-cycle constraint on the regulation of gene expression by platelet-derived growth factor. Science (Wash. DC). 238:1269-1271.

38. Fibbe, W. E., M. R. Daha, P. S. Hiemstra, N. Duinkerken, E. Lurvink, P. Ralph, B. W. Altrock, K. Kaushansky, R. Willemze, and J. H. F. Falkenburg. 1989. Interleukin 1 and poly(rI) p poly $(\mathrm{rC})$ induce production of granulocyte CSF, macrophage CSF, and granulocyte-macrophage CSF by human endothelial cells. Exp. Hematol. 17:229-234.

39. Tannenbaum, C. S., J. A. Major, E. A. Poptic, P. E. Dicorleto, and T. A. Hamilton. 1990. Lipopolysaccharide induces competence gene JE and $\mathrm{KC}$ in Balb/C 3T3 cells. J. Cell. Physiol. 144:77-83.

40. Shyy, Y-J., L. L. Wickham, Y-L Hu, K-L. P. Sung, and S. Chien. 1992. Human monocyte colony stimulating factor increases the adhesion of monocytes to endothelial monolayers: possibly through monocyte chemotactic protein-1. FASEB (Fed. Am. Soc. Exp. Biol.) J. 6(5):A1891.

41. Cybulsky, M. I., and M. A. Gimbrone, Jr. 1991. Endothelial expression of a mononuclear leukocyte adhesion molecule during atherosclerosis. Science (Wash. DC). 251:788-791.

42. Poston, R. N., D. O. Haskard, J. R. Coucher, N. P. Gall, and R. R. Johnson-Tidey. 1992. Expression of intercellular adhesion molecule-1 in atherosclerotic plaques. Am. J. Pathol. 140:665-673.

43. Gimbrone, M. A., Jr., M. P. Bevilacqua, and M. I. Cybulsky. 1990. Endothelial-dependent mechanisms of leukocyte adhesion in inflammation and atherosclerosis. Ann. NY Acad. Sci. 598:77-85.

44. Luscinskas, F. W., M. I. Cybulsky, J-M. Kiely, C. S. Peckins, V. M. Davis, and M. A. Gimbrone, Jr. 1991. Cytokine-activated human endothelial monolayers support enhanced neutrophil transmigration via a mechanism involving both endothelial-leukocyte adhesion molecule-1 and intercellular adhesion molecule-1. J. Immunol. 146:1617-1625.

45. Bochner, B. S., F. W. Luscinskas, M. A. Gimbrone, Jr., N. Walter, S. A. Sterbinsky, C. P. Derse-Anthony, D. Klunk, and R. P. Schleimer. 1991. Addition of human basophils, eosinophils, and neutrophils to interleukin 1-activated human vascular endothelial cells: contributions of endothelial cell adhesion molecules. J. Exp. Med. 173:1553-1556.

46. Montgomery, K. F., L. Osborn, C. Hession, R. Tizard, D. Goff, C. Vassallo, P. I. Tarr, K. Bomsztyk, R. Lobb, J. M. Harlan, and T. H. Pohlman. 1991. Activation of endothelial-leukocyte adhesion molecule 1 (ELAM-1) gene transcription. Proc. Natl. Acad. Sci. USA. 88:6523-6527.

47. Lane, T. A., G. E. Lamkin, and E. Wancewicz. 1989. Modulation of endothelial cell expression of intercellular adhesion molecule 1 by protein kinase C activation. Biochem. Biophys. Res. Commun. 161:945-952.

48. Bath, P. M., S. A. Mayston, and J. F. Martin. 1990. Endothelin and PDGF do not stimulate peripheral blood monocyte chemotaxis, adhesion to endothelium, and superoxide production. Exp. Cell Res. 87:339-342.

49. Chin, Y-H., J-P. Cai, and K. Johnson. 1990. Lymphocyte adhesion to cultured Peyer's patch high endothelial venule cells is mediated by organ-specific homing receptors and can be regulated by cytokines. J. Immunol. 145:36693677. 